Chapter 14

\title{
Perspectives for Diagnosis and \\ Control of Leishmaniasis Based on \\ Volatile Organic Compounds
}

\author{
Jailson Bittencourt de Andrade, \\ Jairo Torres Magalhães Junior, \\ Paulo Roberto Ribeiro Mesquita, \\ Fábio Santos Oliveira, \\ Frederico de Medeiros Rodrigues and \\ Stella Maria Barrouin-Melo \\ Additional information is available at the end of the chapter \\ http://dx.doi.org/10.5772/57279
}

\section{Introduction}

During the pathogenesis of an infectious disease the cells of an infected host interact actively with its pathogen resulting in the production of different chemical metabolites. In the case of Leishmania infection, the pathophysiology of the disease and the final metabolism due to this infection is dependent on the parasite load in different organs, the type of immune response triggered predominantly in the post-infection, nutritional and physiological condition of the animals, among others [1]. In this way variables related to the host and the parasite must be considered together in metabolomics studies.

Metabolomics is the science applied to systematic study of the profile of metabolics, their composition and the dynamics influenced by genetic modifications, physiological stimuli, environmental, nutritional, among other factors. This field of researches shows great potential for the identification of potential biomarkers and metabolic disorders at an early stage.

In the last decade the study of metabolomics has intensified in order to understand the production and excretion of these metabolites, what are the consequences on sick organisms and especially the possibilities and perspectives resulting from this knowledge. Most of the 
studies aim to develop new ways of diagnosing diseases based on identification of volatile organic compounds (VOC) as indicative of pathological states. Diseases such as diabetes, breast cancer, lung cancer and chronic obstructive lung disease, among others, have been target of metabolomics studies [2-4]. These diseases have in common the chronic condition in its pathogenesis, such as in leishmaniasis, and may develop over a long period without the manifestation of clinical indications but with the production of metabolites as biomarkers of the disease.

Different biological samples may be used for metabolomic studies and they commonly vary according to the pathogenesis of the disease and anatomical region with greatest pathological involvement. In the case of visceral leishmaniasis hair is noteworthy as a biological matrix for analysis of VOC resulting from final metabolism of Leishmania infection and due to the ease of sample collection and the nature of the hair follicle, which has the function to secrete and excrete endogenous produced substances [5].

Therefore, the identification of biomarkers in the dogs with visceral leishmaniasis can serve as a painless diagnostic tool with minimal invasivity, which represents a gain in the field of animal welfare and perspectives for disease control.

We emphasize the use of different techniques for the extraction, separation and identification of these VOCs, as well as the use of univariate and multivariate planning in conducting the work. The use chemometric methods allow the analysis of a large number of variables, identifying similarities in complex samples, where several compounds are analyzed simultaneously.

When metabolomics approach is performed on vector-borne diseases, another important aspect is the possibility of the identified VOC act as chemical attractants for vector insects. VOC produced by hosts which are detected by receivers and antennas of the vectors during the search the process of search and location of food are called kairomones [6]. The ability to detect these volatile compounds makes easier specific recognition of the host and increases the radius of food search by the vector. In the case of leishmaniasis VOC produced from final metabolism of Leishmania infection when released into the environment can attract phlebotomine so that the insect feeds from the infected animals, thereby ensuring the dissemination of the parasite and maintenance of disease cycle.

The discovery of attractiveness of these compounds may aid studies about the presence and dispersion of phlebotomine providing subsidies for better understanding of the biology of these insects and in the future to substantiate effective programs to control the disease based on the manipulation of chemical communication of phlebotomine.

The present chapter contributes to a better understanding of the relationship parasite-dogsandfly in visceral leishmaniasis. Here we summarize the importance of studies involving metabolomics, identification of biomarkers for disease diagnosis, the key techniques and methods of extraction and analysis of VOCs, attract sandflies aspects of the VOC and its application in the control of visceral leishmaniasis. 


\section{Canine visceral Leishmaniasis and fisiopathology of VOC released from hair}

Assumed as a neglected disease by World Health Organization [7], visceral Leishmaniasis (VL) are recorded in about 62 world counties and it mainly affects children, elderly and immunodeficient people $[8,9]$. The VL is a parasitic disease with zoonosis character caused in american continent by Leishmania infantum, protozoan transmited between hosts by phlebotomine vector of Lutzomyia longipalpis specie [10].

The VL is considered a serious public health problem due to its complex epidemiological characteristics, different reservoirs involved, besides fast geographic expansion as well as expensive and arduous control [11].

Domestic dog (Canis familiaris) is considered the main reservoir of urban area due to its high susceptibility to pathogen, the strong cutaneous parasitism and the fact that canine cases precedes humans [11-13]. Thus this species is considered protagonist in studies that aim the development of new forms of control and disease prevention.

In the wild, crab-eating fox (Cerdocyon thous), the hoary fox (Lycalopex vetulus), the common opossum (Didelphis marsupialis) and the white-eared opossum (Didelphis albiventris) are used as natural reservoirs of infection and it is common to find positive animals in areas of human habitations which are related to the wild $[9,14]$.

The Lutzomyia longipalpis (Lutz \& Neiva, 1912) is considered the main vector of VL in the American continent and it is widely studied because of its epidemiological importance for the transmission of this disease $[15,16]$.

L. longipalpis is one diptera of Psychodidae family and Phlebotominae subfamily. These phlebotomine insects measure approximately $2-3 \mathrm{~mm}$, the body is quite hairy, light colored (light brown or straw color) and are easily recognized by their behavior of flying with small jumps and landing with half open wings [11].

The only proven way of transmission so far is through the bite of phlebotomine females that ingest amastigote forms with blood meal when it feeds from an infected mammal [9]. After undergoing processing in the digestive tract they are transmitted to other hosts already in the promastigote form while females feed for the second time [15, 17]. On the spot of inoculation an inflammatory process takes place and promastigostes are then phagocytosed by macrophages, then they become amastigotes and multiply until macrophages break up and they are released to spread to the whole body [17].

The consequences, progression and severity of the disease depend on the immune response expressed by the animal, especially the cytokine production profile [1]. Cytokine production profile varies with environmental factors, nutritional and genetic aspects of the parasite like the species, strain and inoculum size [18].

In the early periods of post-infection there are changes in populations of $\mathrm{T}$ lymphocytes and it has been shown that there is a relationship between the pattern of produced cytokines and 
the manifestation of clinical signs [19]. This association is a result of the greater intensity of parasite load, when there is a lower production of Th1 cytokines (Lymphocyte T helper type I) in various organs such as lymph nodes [20], spleen [21], bone marrow [22] and skin [23].

Animals that produce Th1-type response develops immunity against the parasite cell type, resulting in resistance to infection [19]. In these animals there is a predominance of IFN- ${ }_{\gamma}$, TNF$\alpha$ and IL-12 release, which among other things promotes the production and activation of macrophages, nitric oxide and cell apoptosis [24].

Resistant dogs are characterized by low parasitic burden in several organs [25], no development of clinical signs [19], normal erythropoietic and leukopoietic activities [22] and low infectability to phlebotomine [26].

On other hand animals that produce Th2-type (Lymphocyte T helper type II) response are characterized by a humoral immune type response and consequent susceptibility to infection [19]. In these animals there is a predominance of IL4, IL10 and TGF- ${ }_{\beta}$ that inhibit the production of IFN- $\gamma$ and IL-2 then the cell type response [22, 27]. The antibodies produced by humoral response are unable to eradicate the infection resulting in high parasitic burden and expression of clinical signs of disease.

Thus in dogs with active VL the strength of parasite load is directly proportional to the intensity of clinical signs and disease severity (Figure 1). The most important clinical signs are ocular lesions, periocular and cutaneous, kidney diseases and their consequences; respiratory, digestive, cardiovascular and musculoskeletal disorders; hypertrophy of lymphoid organs and hematological disorders [28].

The transmission of Leishmania by dogs seems to be related to the extent of clinical manifestations of disease so how much more clinical signs present higher the ratio of infectivity, which is possibly related with high parasite load in different organs, especially skin and lymph nodes [29].

Histological skin evaluations of animals which show the presence of perifollicular dermatitis with inflammatory infiltration generally extending by the sebaceous glands [30] and a predominance of macrophages, lymphocytes and polymorphonuclear neutrophils [31].

The hair is considered an appendix of the skin performing various functions in the body among which are included the secretion and excretion of endogenously produced substances by several metabolic processes [32].

The emission and accumulation of chemical compounds by hair are well-studied, in both humans and animals, for several purposes, either as indicative of the internal metabolism of drugs [33]; for investigation in toxicological forensic [34]; for evaluation of chemical contaminants [35]; post-treatment accumulation of drugs [36] ; alcohol and drugs abuse [37]; evaluation of trace elements [38]; or for anti-doping investigations [39].

Hair is an interesting sample for standardization of biomarkers because of its role to excrete endogenous substances [5]. Furthermore, the exam of dogs hair allowed to find Leishmania DNA by standard PCR technique, reingorcing its importance for the diagnosis [40]. 


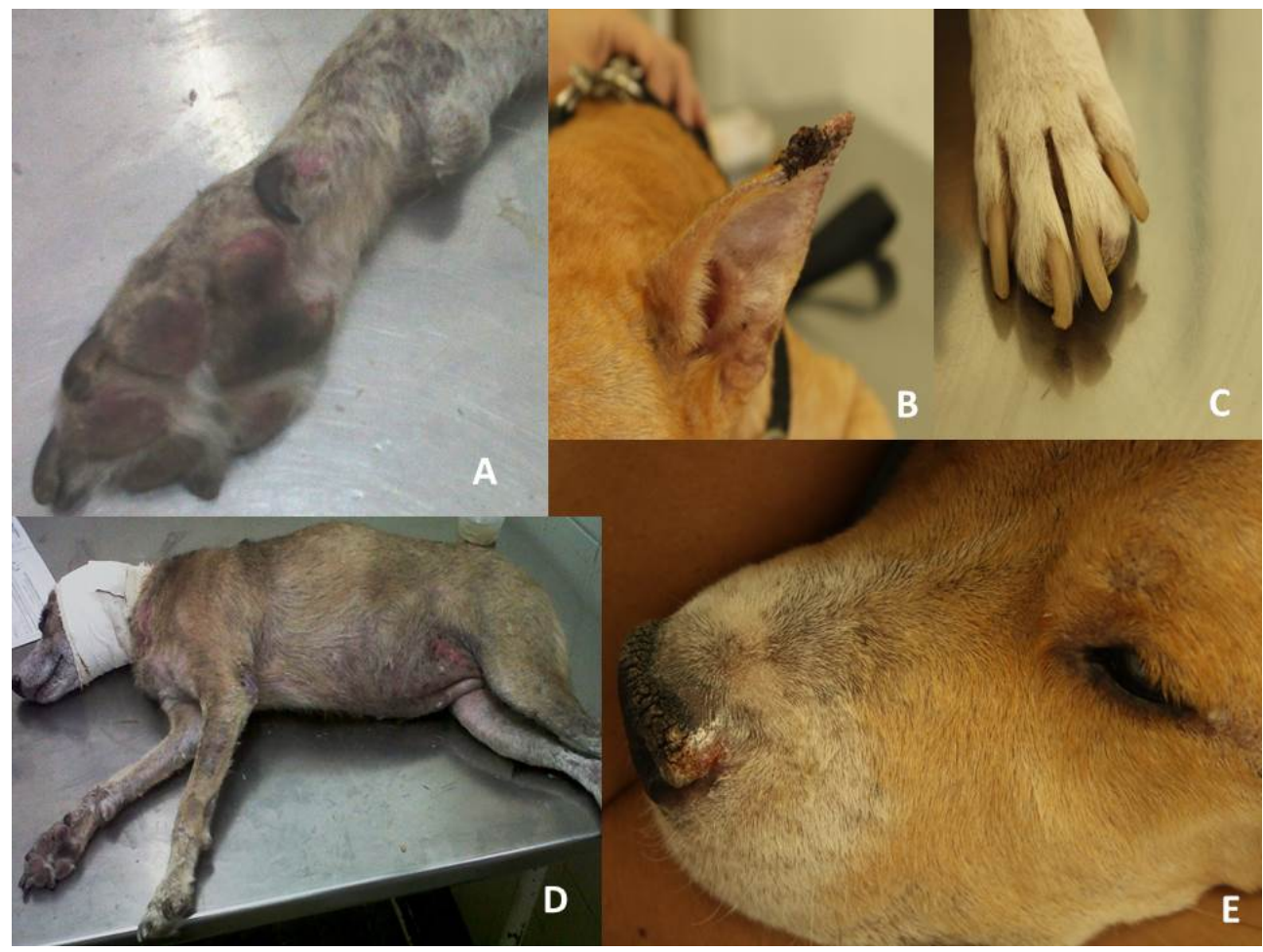

Figure 1. Some clinical signs found in dogs with leishmaniasis: A) Ulcerative erythematous lesions on the plantar surface of the paw; B) Dermatitis tip of ear; C) Onychogryphosis; D) Marked cachexia and generalized exfoliative alopecia; E) Ulcerative nasal mucocutaneous lesions and periocular alopecia.

Following the thought that hair is a biological sample that allows evaluation of internal metabolism of healthy and infected animals, Oliveira et al. [41] demonstrated that volatile organic compounds (VOC) emitted by the dogs clearly differ comparing healthy animals and infected by Leishmania sp., previously identified for ELISA and PCR. In this way, VOC profile also varies due to presence and manifestation of clinical signs for dogs infected by Leishmania sp. [42].

\section{The metabolomics study of its applications}

Due to the current compartmentalization model widespread in human medicine and in veterinary gradually been developed a quest for a embracing perspective in life sciences. This trend is a throwback to ancient times where a holistic perspective was predominant [43]. Biological system, which brings together these ideas, is a term that has a recent origin and currently allows different types of research [44]. This attempt to an expanded approach began 
what the authors call the "omics" age, where genomics, proteomics and metabolomics studies has been carried out (Figure 2) [45].

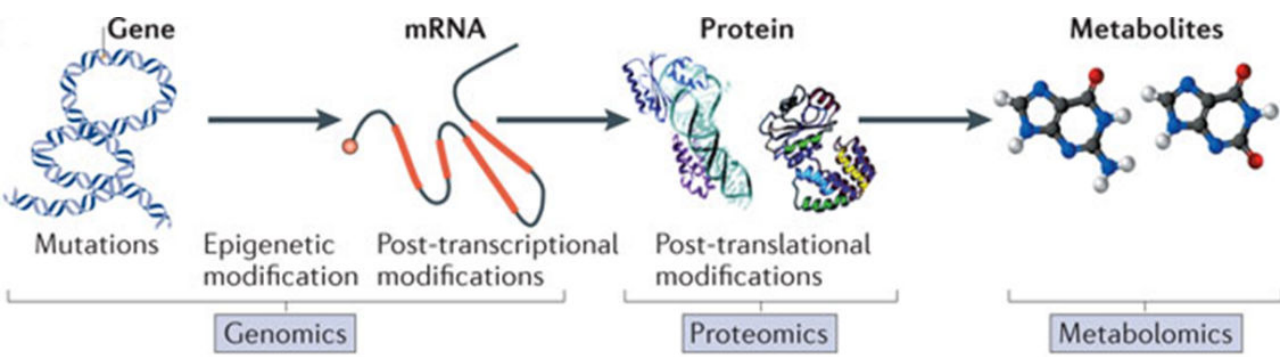

Figure 2. The central dogma of biology and the omic cascade. Adapted of [45].

By definition, genomic characterizes hereditary information of an organism and defines what can happen in a biological system. On other hand, research about proteomics defining the structure and function of the proteins encoded by the genome of an organism is the next logical step for the study of biological systems. Finally, metabolomics systematically analyzes a whole set of chemicals resulting from specific cellular processes, determining the main aspects of the function and regulation of these processes [46].

Metabolomics is also called metabonomics and outlines the study of metabolome [47]. Metabolome in turn is a set of metabolites produced or present in a biological system [47]. Thus, metabolomics can be defined as the study that enables the detection, identification and quantification of the largest number of possible metabolites in biological samples, searching for variations that can be used to discriminate volatile organic compounds between samples [48].

Metabolomics aims to determine a whole set of low molecular weight compounds (less than $1.500 \mathrm{Da}$ ) in a given biological sample, getting closer as much as possible of the physiology of the whole system [49]. For samples obtained from healthy subjects and patients, the aim is to identify one or more endogenous metabolites found in clinical samples related to disease [48].

This approach of combining various faces of a biological system allows integrating different details of this complex information network. Thus, this makes possible application of metabolomics in different approaches, such as the study of basic biological models, drug development, human and animal pathophysiological models, toxicology studies, nutritional effects, metabolic consequences from genetic modifications, inborn errors of metabolism and identification of biomarkers of diseases [45, 47, 50, 51].

Currently, analysis involving metabolomics has been successfully performed in several pathogens that infect living beings, such as lineages of uropathogenic Escherichia coli [52], Hepatitis B [53], the pathogenic fungi Aspergillus fumigatus [54] and protozoan Plasmodium falciparum, the major cause of malaria [55]. According Lakshmanan and Daily [50], metabolomics offers a unique and powerful tool to explore the biology of insects vectors and to develop 
strategies to stop its transmission. It has been shown that in the case of malaria some chemical compounds play a critical role in the development life cycle of P. falsiparum within Anopheles spp. vector and the interruption of the formation of such metabolites could help to reduce disease transmission [56].

In the case of Leishmania sp., most studies involving metabolomics deal mainly with metabolic changes in parasite at cellular level, differences in metabolism pathways of substances, sensitivity and resistance to drugs and other approaches related to the development of the parasite [57-59]. To our knowledge the only work that involves metabolomics with diagnostic purposes was developed in dogs with different clinical profiles for canine visceral leishmaniasis and it was found some of the volatile organic compounds emitted by animals such as potential biomarkers of disease [42].

Metabolomic studies in order to diagnose diseases are quite conducted for other diseases [2, 60]. The idea that chemical components resulting cellular activities can reflect the health status of an individual is old: in China (1500-2000 BC), doctors used ants to detect the presence of glucose in urine of patients with suspected diabetes [43]. The pathophysiological changes observed from metabolomic have a shorter response time in comparison to the development of clinical symptoms for example. This is one of the reasons why metabolomics has been used in an attempt to identify biomarkers for early stage disease, especially those of a chronic nature such as cancer and respiratory diseases, which usually have a later diagnosis [61, 62].

As in metabolomics studies takes into account a systemic approach, theoretically any change in the body, whether physiological or pathological, can influence the results. Thus, to minimize interference unrelated to the objectives of the study it is important that at the experimental design taken into account factors intrinsic and extrinsic to individuals, such as genetic variations, diet, gender, age of individuals, climatic conditions, concomitant infections, among others. Moreover, this multiplicity of effects can be used. For example, metabolomics can be used to identify the impact of nutrients in the diet on the biochemistry of living organisms and their susceptibility / resistance to disease [50].

The metabolites are a wide range of molecular arrangements and that provides a variation in several physical and chemical properties of their components. The degree of diversity is indicated by analysis of organic metabolites with low molecular weight, polar, volatile such as isoprene as nonanol, by analysis of metabolites with higher molecular weight, polar (carbohydrates) and nonpolar (terpenoids and lipid) [63]. To characterize and quantify these compounds is necessary to use specific methodologies and instruments according to the characteristics of each class. Therefore, metabolomics includes several analytical technologies that need to be carefully selected in accordance with the metabolites and metabolic pathway of interest, or the biological question to be answered.

\section{Methods for extraction and determination of VOC emitted by hosts}

Although in many instances scientists do not collect biological samples that they want to analyze, it must be aware about the history of the samples, to procedures for collecting, type 
of packaging, added preservatives, stability characteristics and sample processing, in addition to the conditions storage and delivery protocol [48]. These aim to maintain the chemical profile of substances and physico-chemical characteristics, avoiding losses and minimizing contamination risks.

In metabolomic studies involving the diagnosis of dogs infected by Leishmania sp. the volatile organic compounds emitted from hair of these animals can be used as biomarkers of infection. Research involving VOC emitted from dog has critical steps such as: i) sampling and sample preparation, ii) choice of the extraction method, and iii) choice of analysis method.

\subsection{Sampling and sample storage}

The hair has a large amount of VOC, which can be derived from two sources: endogenous and exogenous. Exogenous VOC adhere to hair according to environmental exposure and the longer the residence time at a given location, the greater the extent of adsorption of these compounds. On other hand, endogenous VOC deriving from internal sources and they are products of host metabolism which when emitted through the skin a fraction is adsorbed by hair. Due to this feature, the hair sample is ideal sample both for outdoor exposure evaluation and for identification of biomarkers of metabolism changes.

When sampling hair it should always be removed from the same anatomical region due to possible variations of VOC profile depending on the area in which the host sample was collected (Figure 3). Sterilized gloves, razors and tweezers should be used in order to avoid sample contamination.

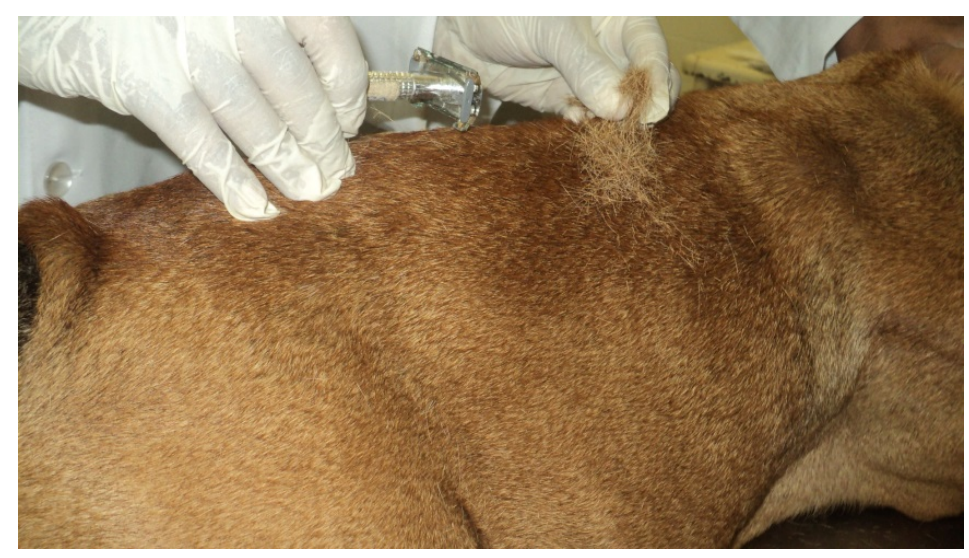

Figure 3. Collect of hair in dorse of dog.

Strategies to reduce exogenous compounds are another important aspect since these compounds can make difficult biomarker identification. For example, dogs can be bathed using mild soap three days before sampling period and the contact of these animals with chemicals must also be avoided. 
After collection, the samples should be stored in clean and sterilized plastic bags kept in freezers at $-20^{\circ} \mathrm{C}$. As VOC tend to desorb from hair in the course of time, the storage at low temperatures minimizes this process. Anyway, the storage of samples for a long period of time should be avoided.

\subsection{Extraction methods}

The hair can contain dozens of VOC with different chemical structures and polarities. Therefore, the ideal extraction technique should be suitable for sampling VOC with quite different properties and to prevent sample contamination during the whole procedure.

Currently, the most used techniques for sampling VOC from biological materials are solvent extraction, steam distillation (SD) and with simultaneous extraction (SDE), supercritical fluid extraction (SFE) solid phase extraction and solid phase microextraction (SPME).

Solvent extraction, SD and SDE are conventional and widely used methods for sampling VOC from biological samples. These methods always require a long extraction time, the use of large amounts of organic solvents and the performance of many steps. In addition, many unstable volatiles compounds such as alkenes, esters and some unsaturated volatile organic compounds may be thermally decomposed and degraded during extraction or distillation at high temperatures [64].

However, these procedures still are widely applied for the characterization of fragrances and flavors since they are direct and less complex. Recently, SFE techniques, adsorbent extraction and SPME have attracted much attention from analysts due to its green and innovative features for sampling VOC from biological samples.

\subsubsection{Solvent extraction}

The solvent extraction is based on the relative solubility of the analyte by an organic solvent. This extraction can be done using a solvent to remove the analytes directly from a solid sample, which typically uses a Soxhlet system.

This extraction technique is perhaps the oldest and has the advantage of being a simple technique with a variety of commercially available pure solvents that provide a wide range of solubility and selectivity. As disadvantages, some of them use large amounts of toxic organic solvents, require a relatively large volume of sample and need ultrapure solvents to avoid sample contamination

The solvent extraction is widely used for sampling of pheromones, because of the lipid nature of many pheromones they are easily dissolved by solvents such as hexane or dichloromethane [65]. When the section of insect that produces pheromone mixture is known, usually a gland may be removed then put in contact with a small volume of solvent for extraction of interesting compounds. However, in this procedure other non-volatile compounds can also be extracted. 


\subsubsection{Steam distillation and extraction by simultaneous distillation}

The SD is the original sampling method of VOC from plants. VOC are extracted from plants using water vapor steam distillation system followed by solvent extraction. The SDE techniques couple steam distillation and solvent extraction in order to simplify experimental procedures, to minimize the use of toxic organic solvents and to reduce the losses that occur during the sample transfer $[66,67]$.

Due to the high temperature during the procedures using SD and SDE, these techniques are not suitable for sampling for VOC from live animals and they can cause thermal decomposition of some thermo-unstable compounds. However, due to the large extraction capacity and the existence of simple SD and SDE experimental devices, they are still considered useful as sampling methods for thermally stable volatile compounds.

Some improvements have been implemented in these conventional sampling techniques to achieve better extraction efficiency. For example, Hashemi et al. [68] combined hydrodistillation with solvent microextraction (HD-SME) for extraction of VOC from Artemisia (a type of plant) and obtained better results than those obtained with conventional hydrodistillation technique. It was also developed by Ferhat et al. [69] a microwave assisted SDE method (MW$\mathrm{SDE})$ for the analysis of volatile compounds form aromatic herbs. This new technique greatly improves the extraction time and amount of organic solvent due to the introduction of microwave energy as a heat source during extraction.

\subsubsection{Supercritical fluid extraction}

SFE is a process of separation and extraction by the use of supercritical fluids as the extraction solvents. Supercritical fluids are considered as a clean solvent, less toxic than organic solvents. Carbon dioxide $\left(\mathrm{CO}_{2}\right)$ is a widely used supercritical fluid to which sometimes a co-solvent is added, such as ethanol or methanol. SFE is a good alternative to liquid-liquid extraction and proved to be an effective technique for sample preparation. Giannuzzo et al. [70] used a mixture of supercritical $\mathrm{CO}_{2}$ with ethanol (15 wt.\%) for extraction of flavonoid naringin from citrus paradise, obtaining better results when compared with pure supercritical $\mathrm{CO}_{2}$.

The advantage of carbon dioxide is that it is easy to remove by simply reducing the pressure, which leaves virtually no trace, also being environmentally friendly [71, 72]. However, the SFE has as main drawback the high cost compared with solvent extraction technique. The carbon dioxide used in SFE has limited power for dissolving polar compounds [73]. The study of new supercritical fluid and the development of small scale SFE instruments are required for application of this technique for the study of VOC from biological samples. The SFE is widely used in the extraction of bioactive compounds from vegetables [74].

\subsubsection{Extraction with adsorbents}

In the extraction with solid adsorbent a pre-purified inert gas is used as carrier gas that flows continuously through the sample and extracts the VOC. Then, the volatile organic compounds are retained on a solid adsorbent, usually Tenax [75]. Finished the extraction time of VOC, an 
organic solvent such as hexane is directed through a tube containing the adsorbent for elution of the compounds. Another possibility is to carry out thermal desorption of VOC retained in the adsorbent tube before analysis.

Different types of adsorbents may be used to obtain a more selective sampling, depending on characteristics of VOC present in the sample. The choice of adsorbents must take into account their specific surface area and ability to retain VOC of interest. If thermal desorption mode is used, it should also be assessed the ability to attain complete and rapid desorption of the analytes, the existence of homogeneous and inert surface to prevent the formation of artifacts and irreversible adsorption during sampling, storage of tubes and desorption; low water affinity to avoid hydrolysis reactions and damage to the stationary phase used for chromatographic analysis, high mechanical and thermal stability [76]. The most used adsorbent materials are sub-classified into activated carbon [77], carbon molecular sieves (Carboxen, Carbosphere e Carbosieve) $[78,79]$ and porous organic polymers (Tenax, Chromosorb e Porapak) [80, 81].

This technique has great potential for the identification of disease biomarkers. Sporing et al. [82] monitored the release of VOC by a lineage of lung cancer cells using solid adsorbents and analysis by thermal desorption and gas chromatography-mass spectrometry (TD-GC/MS) where several aldehydes and ethers were identified.

\subsubsection{Solid-phase microextraction (SPME)}

Solid-phase microextraction (SPME) was developed by Arthur e Pawliszyn [83], it has been regarded as one of the most innovative inventions in the field of VOC extraction in the last years. SPME integrates the steps of extraction, concentration and introduction to analysis, reducing sampling time and increasing the sensitivity when compared to other extraction methods.

This is a technique that has been successfully used for the extraction of compounds from environmental samples [84], pharmaceuticals [85], biological [86] and study of fragrances and flavors [87].

Headspace solid-phase microextraction (HS-SPME) is the most widely used form for sampling VOC from different matrices, including biological samples from animals [88-90], vegetables [91-94] e microbes $[95,96]$.

In recent years, SPME has been applied to the monitoring of compounds in living systems [97]. This application has advantages such as the possibility of sampling compounds without changing the actual condition of the system and to carry out studies about temporal progression of a disease of a subject over time without the need to sacrifice one specimen for each sampling point [98]. For example, Bai et al. [99] used SPME technique in vivo for determination of off-flavor compounds in live fish. Geosmin and 2-methylisoborneol (2-MIB), produced by cyanobacteria and actinomycetes, were quantified in fish muscles which give the flavor of "land" and "clay" to fish. 
In the area of Leishmaniasis there is only one work reported in literature about VOC extraction. HS-SPME was used by de Oliveira et al. [41] for extraction of VOC from hair of dog healthy and infected by Leishmania infantum, followed by GC-MS analysis which detected about 274 compounds, mostly ketones, aldehydes and hydrocarbons

\subsection{Methods of analysis}

After extraction VOC from samples it is necessary to identify each component to obtain quantitative and qualitative information about samples. Since the invention and development of gas chromatography technique the analysis of volatile compounds in biological becomes much easier.

GC is an excellent analytical technique for separating compounds which can be volatilized at the temperature applied to the injector device. Therefore, when GC is coupled to a detector it becomes a powerful technique for analysis of VOC in biological samples [100].

Nowadays gas chromatography coupled to flame ionization detector (GC-FID) and GC-MS are the main techniques used for VOC analysis and the GC-MS technique is more powerful due to the great identification ability of mass spectrometry (MS).

In recent years, the development of multi-dimensional CG has significantly improved separation of VOC from complex samples, making easier than before to obtain bio-information related to compounds present in samples [101]. Bean et al. [102] applied comprehensive twodimensional chromatography coupled to time-of-flight mass spectrometry (GCxGC-TOF-MS) technique to identify the profile of VOC from the metabolism of Pseudomonas aeruginosa bacteria. The method enabled better separation and identification of a wider number of compounds compared to the GC-MS technique, enabling the discovery of 28 new VOC characteristic of $P$. aeruginosa.

Another innovative application was proposed by Stadler et al. [103] that used TD $\times$ GC-TOFMS for the identification of VOC released from a pig carcass, which allowed to define of the profile of compounds released during the decomposition of different tissues

\section{Biomarkers in diagnostic of disease}

Using the techniques of extraction and identification of VOC allows the discovery of biomarkers that are measurable biomolecules that represent the normal physiological state or changes of an individual related with a pathophysiological process or treatment. Generally biomarkers may be (a) proteins that represent the cellular and enzymatic changes or (b) small organic molecules called metabolites. These compounds may help in early detection and monitoring the progress of a disease, and its response to the use of a drug or therapeutic intervention [104].

Currently biomarker discovered using "omics" technologies, such as proteomics and metabolomics wherein sample biochemical profiles, are determined (mainly biofluids) from patients and healthy individuals. Compounds that after an appropriate statistical analysis appear over 
or under-expressed in samples from patients when compared to healthy controls may be considered as potential biomarkers of disease [105].

It is highlighted that finding metabolites present at significantly different levels in samples from patients does not necessarily make them useful biomarkers. The route for the validation and use of biomarkers requires extensive studies. This validation must address two issues: a) the metabolite whose concentration levels differ significantly between samples of a test population is indicative of a specific pathophysiology? b) there is an abnormal level of this specific metabolite clearly stating a specific pathophysiology when all other symptoms are considered? In addition, biomarkers need to provide adequate levels of sensitivity and specificity (> 80\%) for correct detection and classification of disease [106].

The strategy most often used to develop biomarkers involves a discovery phase in a restrict number of samples, followed by validation of biomarker with potential using a larger number of samples from patients before this compound can be adopted as a clinical tool.

The use of chromatographic techniques combined with the power of mass spectrometry allows the identification of dozens of compounds and this when coupled with the large number of samples studied generates an immense amount of data that must be processed, analyzed and interpreted.

The purpose of the data processing is to extract quantitative information from data related to detected metabolites obtained from chromatographic and mass spectrometry. This extracted information can be arranged in an matrix which later be will used in the multivariate analysis[107].

The main multivariate techniques used for biomarker discovery are Principal Component Analysis (PCA), Partial Least-Squares - Discriminant Analysis (PLS-DA) and orthogonal PLSDA (OPLS-DA) [108]. PCA is commonly implemented as a starting point for the data manipulation to obtain an overview about cluster tendencies and to detect outliers.

PLS-DA is used to deal with specific studies class where a linear relationship between metabolites in the matrix $X$ and category information in the matrix $Y$ is established. This technique can enhance the separation of classes and improve the interpretability of statistical models [109]. In OPLS-DA model partition variance matrix X in predictive and non-predictive classes (orthogonal classes) not only improves the discrimination metabolic profiles but also the transparency of models [110].

Many biomarkers of disease from different samples have been discovered by the application of different techniques for extraction and analysis. Table 1 summarizes some of these biomarkers.

Table 1 shows already discovered biomarkers for various diseases such as Melitus diabetes, myocardial ischemia, galactosemia, breast cancer, ovarian carcinoma, renal cell carcinoma, colorectal carcinoma, etc [4]. 


\begin{tabular}{|c|c|c|c|c|}
\hline Sample & Disease & Technique & Biomarkers & References \\
\hline Urine & Colorectal carcinoma & UPLC-TOF-MS & Nucleosides, carnitines & Wang et al [111] \\
\hline Blood serum & Diabetes melitus & LC-MS & $\begin{array}{l}\text { Leucine, isoleucine, valine, } \\
\text { phenylalanine, tyrosine }\end{array}$ & $\begin{array}{c}\text { Wang et al [112] } \\
\text { Langenberg and Savage } \\
\text { [113] }\end{array}$ \\
\hline Blood serum & Type I diabetes & $\begin{array}{l}\text { UPLC and } \\
\text { GC-TOF-MS }\end{array}$ & Lipids and polar metabolites & Oresic et al [114] \\
\hline Urine & $\begin{array}{l}\text { Breast cancer, ovarian } \\
\text { carcinoma, cervical } \\
\text { carcinoma }\end{array}$ & HPLC-MS & Hormones, nucleosides & Woo et al. [115] \\
\hline Blood plasma & Myocardial ischemia & HPLC-MS & $\begin{array}{l}\text { Sugars, ribonucleotides, } \\
\text { amino acids }\end{array}$ & Sabatine et al [116] \\
\hline Dried blood & Galactosemia & LC-MS/MS & Hexose monophosphates & Jensen et al. [117] \\
\hline Blood serum & Renal cell carcinoma & LC-MS & $\begin{array}{l}\text { Phospholipids, phenylalanine } \\
\text { and cholesterol metabolites }\end{array}$ & Liu et al. [118] \\
\hline $\begin{array}{l}\text { Blood plasma } \\
\text { and serum }\end{array}$ & Onchocerciasis & LC-MS & $\begin{array}{l}\text { Fatty acids, protein, sterol } \\
\text { lipid, etc }\end{array}$ & Denery et al. [119] \\
\hline Breath & Lung cancer & GC-TOF-MS & $\begin{array}{l}\text { Propane,carbon disulfide, 2- } \\
\text { propenal, ethylbenzene and } \\
\text { isopropyl alcohol }\end{array}$ & Rudnicka et al. [120] \\
\hline Breath & Cysticfibrosis & GC-MS & Carbonyl sulphide, alkanes & Phillips et al. [121] \\
\hline Breath & $\begin{array}{l}\text { Chronic ostructive } \\
\text { pulmonary disease }\end{array}$ & TD-GC-TOF-MS & $\begin{array}{l}\text { Hexanal, nonanal, decanal, } \\
\text { undecanal, pentadecanal, } \\
\text { dodecanal, etc }\end{array}$ & Basanta et al. [3] \\
\hline Urine & Lung cancer & GC-MS & $\begin{array}{l}\text { 2-heptanone, o-toluidine, } \\
\text { nitromethane, etc }\end{array}$ & Matsumura et al. [122] \\
\hline
\end{tabular}

Table 1. Biomarkers identified for different diseases.

Most of the identified biomarkers are non-volatile, such as proteins, lipids and other high molecular weight compounds. However, several volatile biomarkers have been discovered in recent years.

In this context, the discovery of VOC that may serve as biomarkers of infectious diseases such as leishmaniasis is presented as a promising possibility. The first work in this direction has been reported in the literature by Oliveira et al. [41] which proposed a noninvasive diagnostic method for detection of visceral leishmaniasis in dogs. HS-SPME/GC-MS techniques were developed and applied to identify the VOC emitted from hair of 8 healthy dogs and 16 dogs infected by Leishmania infantum and 274 compounds were detected (Figure 4). 


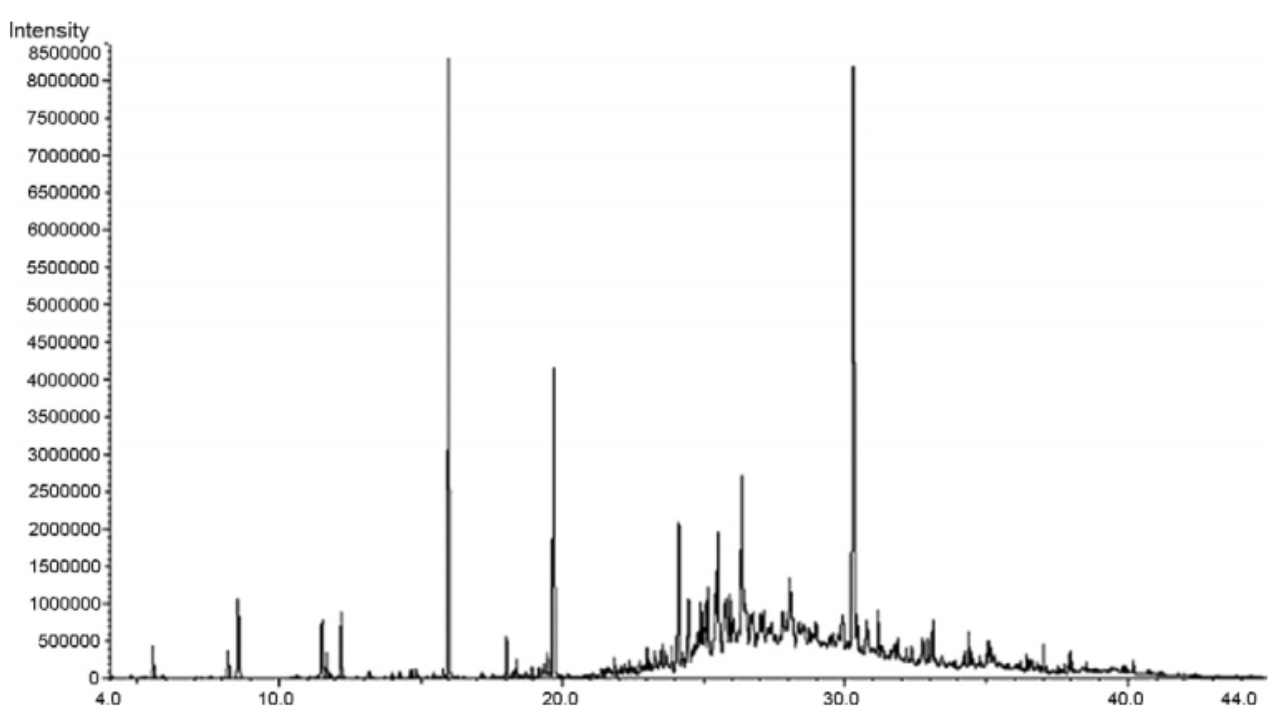

Figure 4. Chromatograms obtained by HS-SPME/GC-MS analysis of canine hair samples, for all VOC [41].

So, multivariate Principal Component Analysis (PCA) and Soft Independent Modeling of Class Analogy (SIMCA) were used to discriminate healthy and infected groups of dogs. Figure 5 shows the PCA scores graph.

The majority of identified VOC belonged to the class of ketones, aldehydes and hydrocarbons, and compounds such as benzaldehyde, 2-hexanone and 2,4-nonadienal showed greater discriminatory power between the two groups, therefore potential this later compounds are candidates for biomarkers of canine visceral leishmaniasis.

Continuing this work, Magalhães-Junior et al [42] investigated that the profile of VOC emitted from infected dogs change according to symptomatology or not of their conditions. For this 36 dogs living in endemic areas for leishmaniasis were studied, which were divided into three groups according to (1) absence of the disease, (2) presence of clinical infection or (3) subclinical Leishmania infantum. In this study, infection was confirmed for parasitological test by culture and microscopy and PCR.

The authors used HS-SPME/GC-MS techniques for identification of VOC from dogs and after multivariate analysis using PCA and PLS-DA they found that the profile of these compounds emitted differ between the three groups. There still differences among infected dogs showing clinical disease from those with subclinical infection. They were also identified 10 new compounds with potential use as biomarkers of infection. These studies show that the use of VOC as biomarkers of infection by Leishmania sp. as a promising approach. However, many studies must still be performed until confirmation of biomarkers capable of being used in clinical practice, including potential application for humans. 


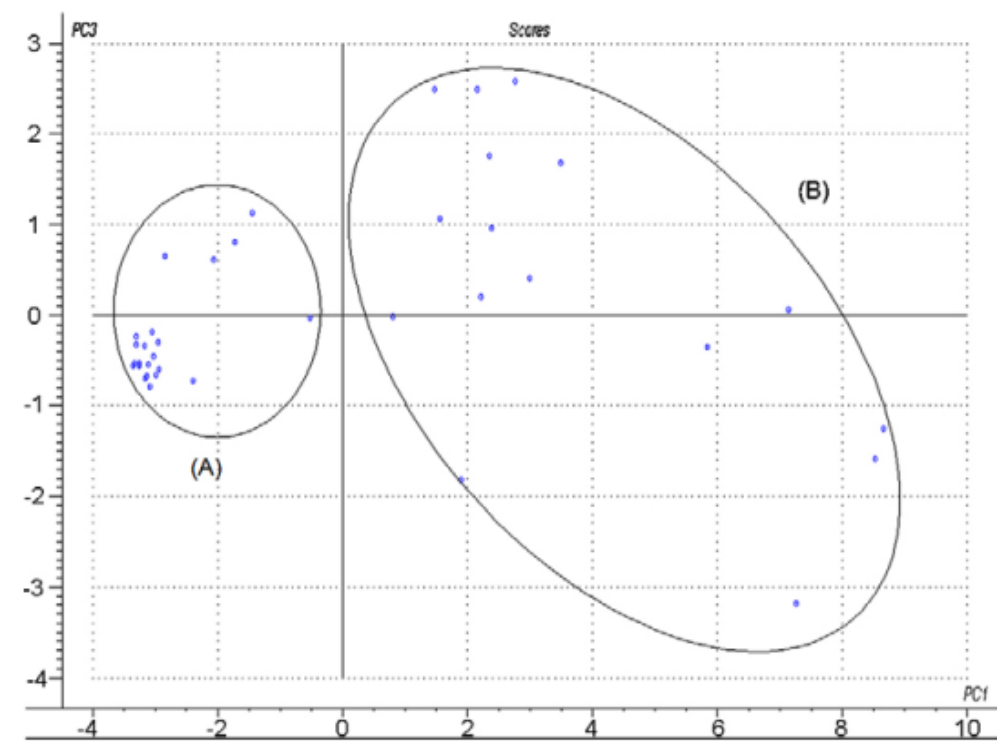

Figure 5. PCA scores graph based on chromatographic peak areas of VOC of the hair of leishmaniasis infected (A) and non-infected dogs (B) [41].

\section{Attraction of phlebotomine to volatile organic compounds}

It is well known that insects use olfactory and visual stimuli during different stages of its life cycle like for the search for a blood source or suitable place for oviposition [123]. In the case of olfactory stimuli, the orientation of these insects towards the sources of attractive odors depends on the time and space distribution of odorant molecules spread on the environment. The molecules associated with olfactory responses are volatile organic compounds that disperse following the gas laws, forming clouds of odors and are responsible for chemical communication between the vector insect and host [124].

\subsection{Chemical ecology of insects}

The chemical communication occurs when an individual (transmitter) sends chemicals which are transmitted through a medium (air, water, substrate) and are captured by another individual (receiver). These chemicals are called semiochemicals and can be toxins, nutrients, or the substances responsible for the proper transmission of information, infochemicals [125].

Infochemicals are chemical substances that provide information during the interaction between two individuals, resulting in a behavior or physiological response of the receptor. Communication is considered intraspecific when infochemicals called pheromones are secreted by an individual and released to the environment, resulting on a specific behavior reaction of another individual of the same specie [6]. 
The substances involved in the case of interspecific communication are called allelochemicals and are classified based on harm and benefits to the organisms. The kairomone is a type of allelochemicals which evokes an adaptive response that is unfavorable to the transmitter, but favorable to the receiver [6]. Typical example of kairomone are the volatile organic compounds produced by hosts and are detected by receivers and antennae of insects during the search process and location of food source [126]. The ability to detect these volatile compounds makes easier the specific recognition of the host and increases the range foraging by the vector [127].

Several animals produce a huge number of volatile compounds derived from their own skin, breathing, urine and feces. The detectability of these substances by receivers depends upon the amount that are produced and dispersed over the environment, distance between the insect and the host; wind speed, turbulence and specificity of these molecules to receptor cell of insects which are primarily present in the antennas of insects [128].

The importance of some chemical compounds to the guidance of hematophagous insects has been demonstrated. Carbon dioxide is a by-product of cellular respiration that is released in large amounts by potential hosts and it is a wildly studied semiochemical such as its attractive effect has already been reported for Aedes aegipty [129], Culex quinquefasciatus [130], Lutzomyia sandflies [131] and some species of tsetse fly (Glossina spp.) [132]. Another extensively studied compound is 1-octen-3ol which was initially identified from volatile compound of expiration of bovine animals and its attractive effect was evaluated in several species of hematophagous insects [123], including sandflies [124]. Lactic acid is the main component of human sweat and effect was evaluated, being considered attractive when used together with $\mathrm{CO}_{2}[133]$.

These chemical compounds are produced in large scale by several species of animals, therefore they can be regarded as universal kairomones. They attract insects that have opportunistic feeding habits, since they indicate the presence of live vertebrate at a nonspecifically way [134]. Additionally, these orientation behaviours are complicated and potentially plastic, may be modulated by environmental factors [135].

\subsection{Chemical ecology of phlebotomines}

Among the studies performed to identify VOC involved in chemical communication of phlebotomines most of them use L. longipalpis as target species, which is why there are few knowledge about other species of phlebotomines.

In the late 80 s the sex pheromone of L. longipalpis was discovered and since then many studies have been carried out. The pheromone is produced in glandular tissue located in the abdomen of males $[136,137]$ and is primarily composed of terpenes, a class of natural products that contains in their structure three or four isoprene units with five carbon atoms. More recent works have shown that there are differences in the chemical composition of the sexual pheromone according to the geographical location of L. longipalpis the male that produces it, suggesting that this variation is a result of reproductive isolation [138]. This result supports the hypothesis that the L. longipalpis is formed by a complex of cryptic species with different morphological and behavioral characteristics [139, 140]. 
Despite the proven efficacy of sexual pheromone for attraction of L. longipalpis by both laboratory [141] as well as field studies [142], this variation in chemical composition restricts the practical use of pheromone at different locations, increasing the importance of the study of kairomones for chemical ecology of phlebotomines. Furthermore, Bray e Hamilton [143] when conducting behavioral studies in the laboratory, they found that the attractiveness of females of L. longipalpis nearly doubled when the odor of hosts was added to sex pheromone.

Even so, there are few studies in the literature that evaluate the attractiveness of the phlebotomine to host odors. For example, Hamilton and Ramsoondar [144] found that females and males of $L$. longipalpis were attracted by emitted volatile organic compounds from human skin and there was a difference in attractiveness among the volunteers.

Likewise Rebollar-Tellez et al. [145] found different levels of attractiveness to human volunteers, suggesting that this variation may be due to different VOCs emitted by humans. It was also observed that females of L. longipalpis preferred to bite human's ear over other parts of the body, considering the number of bites over the exposed area. It has been shown that insects were attracted by odors extracted from human ear, showing that this preference is related to the VOC emitted this region of body [145]. Also in this work, females of L. longipalpis coming from the city of Jacobina (Bahia, Brazil) were more anthropophilic than insects from other geographical locations (Marajó, Pará, Brazil and Curiágua, Venezuela). This difference in response of female of L. longipalpis from different sites was also found by Rebollar-Tellez et al. [146] suggesting that there is a local adaptation of the complex of L. longipalpis species to particular hosts or to a specific set of odors and this behavior is inborn and genetically controlled.

For other host species it had been shown that sixteen chemical compounds from anal and caudal glands of European foxes (Vulpes vulpes) perform electrophysiological and behavioral action on L. longipalpis [147], suggesting that there is a complexity of components that can act on chemical communication between hosts and phlebotomines.

It has been observed that in the case of canine VL phlebotomines are more attracted to feed from infected dogs than from healthy dogs and this preference is probably related to the different odors emitted by infected animals [128]. As demonstred by Oliveira et al. [41], in fact volatile organic compounds emitted by the dog clearly differ between animals infected by Leishmania sp. and healthy ones, previously identified for ELISA and PCR. O'Shea et al. [148] when studying the attractiveness of L. longipalpis to hamsters it was observed that the vector is more attracted by individuals infected by Leishmania infantum in comparison with healthy ones. After analyzing the volatile organic compounds emitted by rodents using gas chromatography O'Shea et al. [148] described the presence of 10 chromatographic peaks of substances in infected animals which were not detected in those healthy.

\subsection{Main techniques used for chemical ecology of phlebotomines}

The insects have a well developed sense of smell which odors are mainly picked up by the antennae for the detection and discrimination of chemical compounds present in the environment. This signal reception in most insects is performed by sensilla, small hairs that are located 
in the antennae, and is processed as follows: when the molecules responsible for the emission of odors reach the antennae sensilla they cross through the cuticle pores until they attain sensillum lymph where they bind to odors ligand protein and they are carried to receiving neuron, generating a cation flow through the membrane of the axon which is then converted to electrical stimulation [149]. This electrical stimulation can be measured by a technique known as electroantennography, wherein the insect antenna is used as a detector of chemical substances. In this technique the amplitude of the voltage produced by the stimulus increases proportionally with concentration of the substance until saturation threshold is reached.

The electroantennography is a sensitive and specific technique since the insect antenna is much more sensitive than equipments usually used for the detection of chemical substances, therefore it is able to detect minimum amounts of a particular substance.

To identify which VOC present in particular extract exhibit biological activity on L. longipalpis gas chromatography coupled to an electroantennographic detector (GC-EAD) can be used, which is an instrument capable of separating the organic compounds present in the sample and measuring electrical signals emitted by antennae of insects used as biological detectors (Figure 6).

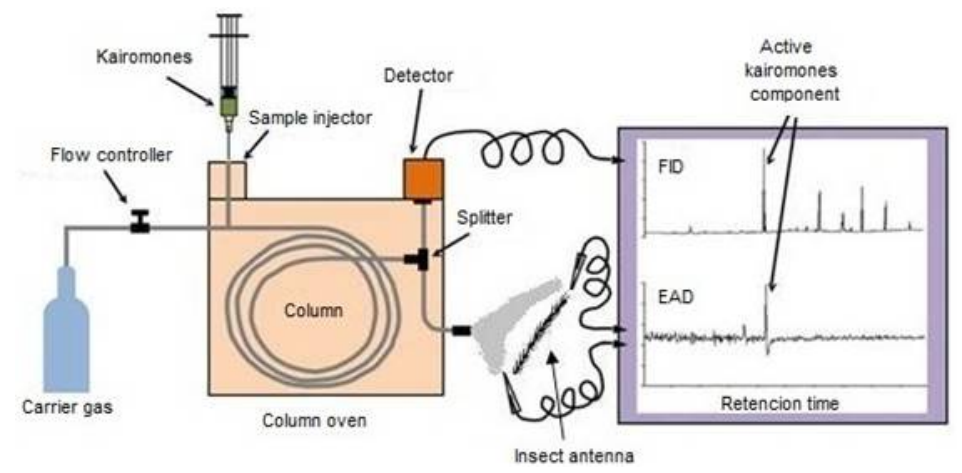

Figure 6. Gas chromatograph coupled with flame ionization detector and electroantennogram recorder, adapted of [150].

Thus, by inserting the sample into the GC injector it is vaporized and the compounds are transported by a carrier gas traveling across the chromatographic column where separation of substances is performed. When leaving the chromatographic column the flow is splitted into two and one part goes to the detector that identifies the chemical compound and the other part goes to the electroantennographic detector. In this way, the first detector provides a chromatogram containing all compounds detected while the second detector produces an electroantennogram exhibiting only the compounds that are biologically active to that insect (Figure 6).

This technique has been used successfully in several studies involving chemical ecology of insects, especially to search for compounds which are used for agricultural pest management [151, 152]. In research involving phlebotomines this procedure has also been used [147, 153], 
but it is underexplored and still needs further study due to the great potential for discoveries [154]. The electroantennography serves to specify which compound the insect actually reacts [155]. However, to specify the biological role of this compound laboratory bioassays and field tests must be carried out.

The laboratory bioassays are conducted in closed systems attempting to obtain data about the behavior of insects when they are induced to respond to a chemical stimulus. Bioassay in the detector is a living organism or part of your sensory system. In bioassay the detector is a living being or part of its sensory system. For the realization of bioassays can be used olfactometers, wind tunnels, testing arena, among others. It is important to highlight that the design and size of these apparatus vary greatly depending on the size and biological characteristics of eachinsect.

There are several advantages of performing bioassay under laboratory conditions compared to field tests: (I) control of environmental conditions, (II) control of the physiological conditions of the organism, (III) elimination of external stimuli, (IV) better interpretation of complex responses.

The bioassay most widely used for phlebotomines is the wind tunnel. In this methodology the flight of insects is allowed while they follow a track of chemical compounds established by an air current which is released on the opposite side where the insects are arranged (Figure 7). The behavior of the insect due to this stimulus is recorded by direct observation or by video cameras and special software. The first wind tunnel study using L. longipalpis phlebotomine species was performed by Morton and Ward [136] in which the authors found that virgin females aged 3-6 days came faster and in greater numbers to the other side of the tunnel when they were used hamster and pheromone extracted from attractive males as compared to the control. For these tests it was used a wind tunnel of $240 \mathrm{~cm}$, but since then, relatively few studies have been conducted using this methodology [147, 148, 153, 156].

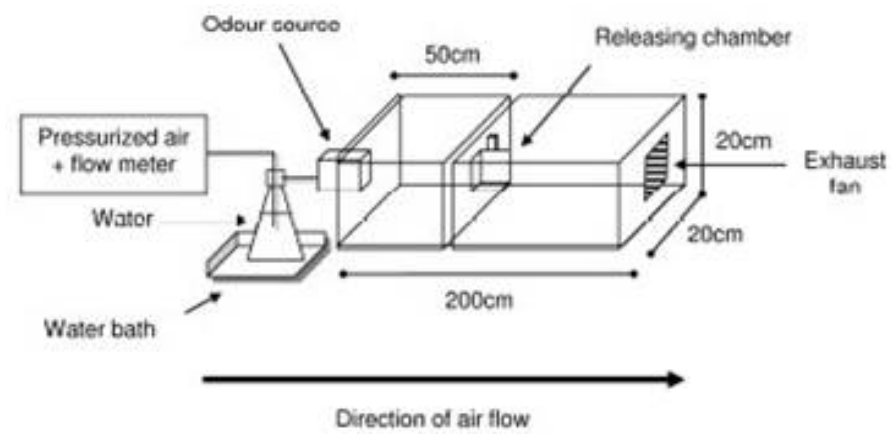

Figure 7. Schematic drawing of wind tunnel [156]

Despite several advantages, bioassays have significant drawbacks: (I) organisms up under laboratory conditions may have different behaviors compared with wild organisms, (II) environment standardization in the laboratory is scarcely repeated at field conditions. Thus, field tests are considered as essential for the validation of a semiochemical and they are the 
final phase for determining the attraction of phlebotomines to a compound or mixture of compounds. In these studies chemical compounds are placed as bait in traps and their own attractiveness is tested in a proven endemic area for the particular studied insect [124].

\subsection{Application of chemical ecology for vector control}

Despite recurrent attempts to control and prevent visceral Leishmaniasis, it is booming worldwide, particularly in Brazil [7, 8].

The situation becomes more alarming when it evaluates the current trend towards urbanization of the disease [10], associated with increasing environmental degradation that favors its spread [157], as well as exposure of susceptible populations and the ineffectiveness of current measures to combat disease [158].

Currently, vector control is based only on the use of environmentally-destructive chemical insecticides [159], however this measure is highly debatable due the risks of environmental contamination and development of resistant insects [160]. Thus, the vector control based on chemical manipulation of vectors is gaining prominence.

In this direction, the identification of semiochemical that can be used as bait in traps to capture phlebotomine can provide a significant improvement for disease control. Light traps are commonly used to monitor populations of phlebotomines and are important for several reasons: (I) enable early identification of the presence of disease vectors in areas previously considered as non-transmission, making it easier to decision making authorities, (II) allow the knowledge about distribution of the vector in a given region as well as monitoring the spread of vector in these locations, (III) and finally, they allow a better understanding of the relationship between parasite, phlebotomine and environment, thus maximizing the attempts to control the disease.

The trap advocated for capture of phlebotomines is the CDC light [11] and these traps have some operational limitations such as the high cost, little specific and contestable accuracy for areas with low phlebotomines occurrence [161]. The use of chemical compounds along with traps aims to make them more specific and efficient, which has also been demonstrated in studies of phlebotomine [124, 162, 163], as well as other insect vectors of diseases [164, 165].

Another option arising from the identification of semiochemicals attractive to phlebotomine is their use integrated with insecticides. The use of semiochemicals with insecticides to control sand fly populations would be an example of integrated vector control. Similar techniques are used to control agricultural pests [152, 166]. Configures as an ecological approach for the control of insect vectors of disease and it is a rational and integrated use of various techniques available and necessary to a unified program.

The use of semiochemicals in integrated vector management reduces the amount of insecticide used, reducing accidents and environmental risks to public health, as well as decreasing risks of development of resistance in insects. The use of semiochemicals has other advantages, such as focus control on single specie, since most compounds is specie-specific, nontoxic, need to be used in small amounts and are biodegradable 
In the case of phlebotomines control, Bray et al. [167] used sex pheromone of L. longipalpis as attractive on walls treated with insecticides and sticky traps, obtaining satisfactory results. However more studies are needed to increase the efficiency of the system, including the use of host odors to maximize the attraction of insects.

\section{Conclusion}

In this chapter we discuss the possibility of studying visceral leishmaniasis from a metabolomics approach aiming to identify VOC from dogs that can be used as biomarkers of early infection. Studies such as these can contribute for the development of a new diagnostic method which is painless, of minimal invasiveness and able to detect infection even before the animals manifest clinical signs.

In general the results from biological samples such as hair demonstrated high dispersion. This variation is expected, since the matrix is not uniform and several factors intrinsic to samples can influence the analysis. Randomized controlled studies that consider gender, race and age as potential confounding variables are needed to minimize the diversity of competing effects and to highlight subtle differences of expression of odor molecules between several clinical profiles, immunological and parasitological of dogs.

In general the results from biological samples such as by, demonstrated a marked degree of dispersion. This variation is expected, since the matrix is not uniform, and several intrinsic factors can influence the samples in the analysis. To minimize the multiplicity of competing effects and better highlight the differences more subtle expression of odor molecules between different clinical profiles, immunological and parasitological dogs are needed randomized controlled studies that consider gender, race and age as potential confounding variables.

\section{Author details}

Jailson Bittencourt de Andrade ${ }^{1}$, Jairo Torres Magalhães Junior ${ }^{2}$, Paulo Roberto Ribeiro Mesquita ${ }^{1,3}$, Fábio Santos Oliveira ${ }^{4}$, Frederico de Medeiros Rodrigues ${ }^{3}$ and Stella Maria Barrouin-Melo ${ }^{2}$

1 Instituto de Química, Universidade Federal da Bahia, Campus Universitário de Ondina, Salvador, Brasil

2 Laboratório de Infectologia Veterinária, Hospital de Medicina Veterinária, Universidade Federal da Bahia (UFBA), CEP Salvador, Bahia, Brasil

3 Empresa Baiana de Desenvolvimento Agrícola S.A. (EBDA), Ondina, Salvador, Brasil

4 Centro de Ciências da Saúde, Universidade Federal do Recôncavo da Bahia, Cajueiro, Santo Antônio de Jesus, Brasil 


\section{References}

[1] Barral-Netto M, Barral A, Brownell CE, Skeiky Y, Ellingsworth LR, Twardzik DR, et al. Transforming growth factor-beta in leishmanial infection: a parasite escape mechanism. Science. 1992;257(5069):545-8.

[2] Phillips M, Cataneo RN, Saunders C, Hope P, Schmitt P, Wai J. Volatile biomarkers in the breath of women with breast cancer. Journal of Breath Research. 2010;4(2): 026003.

[3] Basanta M, Ibrahim B, Dockry R, Douce D, Morris M, Singh D, et al. Exhaled volatile organic compounds for phenotyping chronic obstructive pulmonary disease: a crosssectional study. Respiratory research. 2012;13(1):72.

[4] Kartsova L, Obedkova E. Chromatographic and electrophoretic profiles of biologically active compounds for the diagnosis of various diseases. Journal of Analytical Chemistry. 2013;68(4):291-9.

[5] Harkey M. Anatomy and physiology of hair. Forensic science international. 1993;63(1):9-18.

[6] Vilela ED-L, T. Introdução aos semioquímicos e terminologia. In: HOLOS, editor. Feromônios de insetos: Biologia, química e emprego no manejo de pragas. Ribeirão Preto2001. p. 9-12.

[7] Organization WH. Leishmaniasis: worldwide epidemiological and drug access update. In: WHO, editor. Geneva, Switzerland2011.

[8] Alvar J, Vélez ID, Bern C, Herrero M, Desjeux P, Cano J, et al. Leishmaniasis worldwide and global estimates of its incidence. PloS one. 2012;7(5):e35671.

[9] Quinnell RJ, Courtenay O. Transmission, reservoir hosts and control of zoonotic visceral leishmaniasis. Parasitology. 2009;136(14):1915-34.

[10] Lainson R, Rangel EF. Lutzomyia longipalpis and the eco-epidemiology of American visceral leishmaniasis, with particular reference to Brazil: a review. Memorias do Instituto Oswaldo Cruz. 2005;100(8):811-27. Epub 2006/01/31.

[11] Brasil. Manual de Vigilância e Controle da Leishmaniose Visceral. In: Saúde Md, editor. Brasília: Editora do Ministério da Saúde; 2006. p. 120.

[12] Monteiro EM, da Silva JC, da Costa RT, Costa DC, Barata RA, de Paula EV, et al. [Visceral leishmaniasis: a study on phlebotomine sand flies and canine infection in Montes Claros, State of Minas Gerais]. Revista da Sociedade Brasileira de Medicina Tropical. 2005;38(2):147-52. Epub 2005/04/12. Leishmaniose visceral: estudo de flebotomineos e infeccao canina em Montes Claros, Minas Gerais.

[13] Silva AV, Paula AA, Cabrera MA, Carreira JC. [Leishmaniasis in domestic dogs: epidemiological aspects]. Cadernos de saude publica / Ministerio da Saude, Fundacao 
Oswaldo Cruz, Escola Nacional de Saude Publica. 2005;21(1):324-8. Epub 2005/02/05. Leishmaniose em caes domesticos: aspectos epidemiologicos.

[14] Sherlock IA. Ecological interactions of visceral leishmaniasis in the state of Bahia, Brazil. Memorias do Instituto Oswaldo Cruz. 1996;91(6):671-83. Epub 1996/11/01.

[15] Soares RP, Turco SJ. Lutzomyia longipalpis (Diptera: Psychodidae: Phlebotominae): a review. Anais da Academia Brasileira de Ciencias. 2003;75(3):301-30. Epub 2003/08/30.

[16] Rangel EF, Vilela ML. Lutzomyia longipalpis (Diptera, Psychodidae, Phlebotominae) and urbanization of visceral leishmaniasis in Brazil. Cadernos de saude publica / Ministerio da Saude, Fundacao Oswaldo Cruz, Escola Nacional de Saude Publica. 2008;24(12):2948-52. Epub 2008/12/17.

[17] Gontijo CMF, Melo MN. Visceral Leishmaniasis in Brazil: current status, challenges and prospects. Revista Brasileira de Epidemiologia. 2004;7(3):338-49.

[18] Grimaldi G, Tesh R. Leishmaniases of the New World: current concepts and implications for future research. Clinical microbiology reviews. 1993;6(3):230-50.

[19] Pinelli E, Killick-Kendrick R, Wagenaar J, Bernadina W, Del Real G, Ruitenberg J. Cellular and humoral immune responses in dogs experimentally and naturally infected with Leishmania infantum. Infection and immunity. 1994;62(1):229-35.

[20] Alves CF, de Amorim IF, Moura EP, Ribeiro RR, Alves CF, Michalick MS, et al. Expression of IFN- $\gamma$, TNF- $\alpha$, IL-10 and TGF- $\beta$ in lymph nodes associates with parasite load and clinical form of disease in dogs naturally infected with $<\mathrm{i}>$ Leishmania $</ \mathrm{i}>(<$ $\mathrm{i}>$ Leishmania $</ \mathrm{i}>$ ) $<\mathrm{i}>$ chagasi $</ \mathrm{i}>$. Veterinary immunology and immunopathology. 2009;128(4):349-58.

[21] Kenney RT, Sacks DL, Gam AA, Murray HW, Sundar S. Splenic cytokine responses in Indian kala-azar before and after treatment. Journal of Infectious Diseases. 1998;177(3):815-9.

[22] de Abreu RT, das Graças Carvalho M, Carneiro CM, Giunchetti RC, Teixeira-Carvalho A, Martins-Filho OA, et al. Influence of Clinical Status and Parasite Load on Erythropoiesis and Leucopoiesis in Dogs Naturally Infected with Leishmania (Leishmania) chagasi. PloS one. 2011;6(5):e18873.

[23] Souza DM, Oliveira RCd, Sá RG, Giunchetti RC, Carvalho ATd, Martins Filho OA, et al. Cytokine and transcription factor profiles in the skin of dogs naturally infected by Leishmania (Leishmania) chagasi presenting distinct cutaneous parasite density and clinical status. 2011.

[24] Carrillo E, Moreno J. Cytokine profiles in canine visceral leishmaniasis. Veterinary immunology and immunopathology. 2009;128(1):67-70. 
[25] Manna L, Reale S, Vitale F, Gravino AE. Evidence for a relationship between< i> Leishmania $<$ i $>$ load and clinical manifestations. Research in veterinary science. 2009;87(1):76-8.

[26] Travi BL, Tabares CJ, Cadena H, Ferro C, Osorio Y. Canine visceral leishmaniasis in Colombia: relationship between clinical and parasitologic status and infectivity for sand flies. The American journal of tropical medicine and hygiene. 2001;64(3-4): 119-24. Epub 2001/07/10.

[27] Sato N, Ahuja SK, Quinones M, Kostecki V, Reddick RL, Melby PC, et al. Cc Chemokine Receptor (Ccr) 2 Is Required for Langerhans Cell Migration and Localization of T Helper Cell Type 1 (Th1)-Inducing Dendritic Cells Absence of Ccr2 Shifts the Leishmania major-Resistant Phenotype to a Susceptible State Dominated by Th2 Cytokines, B Cell Outgrowth, and Sustained Neutrophilic Inflammation. The Journal of experimental medicine. 2000;192(2):205-18.

[28] Barrouin-Melo SM, Larangeira DF, de Andrade Filho FA, Trigo J, Juliao FS, Franke $\mathrm{CR}$, et al. Can spleen aspirations be safely used for the parasitological diagnosis of canine visceral leishmaniosis? A study on assymptomatic and polysymptomatic animals. Vet J. 2006;171(2):331-9. Epub 2006/02/24.

[29] Michalsky ÉM, Rocha MF, da Rocha Lima ACVM, França-Silva JC, Pires MQ, Oliveira FS, et al. Infectivity of seropositive dogs, showing different clinical forms of leishmaniasis, to Lutzomyia longipalpis phlebotomine sand flies. Veterinary parasitology. 2007;147(1-2):67-76.

[30] Solano-Gallego L, Fernandez-Bellon H, Morell P, Fondevila D, Alberola J, Ramis A, et al. Histological and Immunohistochemical Study of Clinically Normal Skin of $<\mathrm{i}>$ Leishmania infantum $</ \mathrm{i}>$-infected Dogs. Journal of comparative pathology. 2004;130(1):7-12.

[31] Verçosa B, Lemos C, Mendonça I, Silva S, De Carvalho S, Goto H, et al. Transmission potential, skin inflammatory response, and parasitism of symptomatic and asymptomatic dogs with visceral leishmaniasis. BMC veterinary research. 2008;4(1):45.

[32] Stenn K, Paus R. Controls of hair follicle cycling. Physiological reviews. 2001;81(1): 449-94.

[33] Gratacos-Cubarsi M, Castellari M, Valero A, Garcia-Regueiro J. Hair analysis for veterinary drug monitoring in livestock production. Journal of Chromatography B. 2006;834(1):14-25.

[34] Vincenti M, Salomone A, Gerace E, Pirro V. Application of mass spectrometry to hair analysis for forensic toxicological investigations. Mass spectrometry reviews. 2012.

[35] Agusa T, Kunito T, Iwata H, Monirith I, Chamnan C, Tana TS, et al. Mercury in hair and blood from residents of Phnom Penh (Cambodia) and possible effect on serum hormone levels. Chemosphere. 2007;68(3):590-6. 
[36] Dorea J, Costa J, Holzbecher J, Ryan D, Marsden P. Antimony accumulation in hair during treatment of leishmaniasis. Clinical chemistry. 1987;33(11):2081-2.

[37] Kintz P, Villain M, Cirimele V. Hair analysis for drug detection. Therapeutic drug monitoring. 2006;28(3):442-6.

[38] Pasa S, Kargin F, Bildik A, Seyrek K, Ozbel Y, Ozensoy S. Serum and hair levels of zinc and other elements in dogs with visceral leishmaniasis. Biological trace element research. 2003;94(2):141-7.

[39] Anielski P. Hair analysis of anabolic steroids in connection with doping control-results from horse samples. Journal of Mass Spectrometry. 2008;43(7):1001-8.

[40] Belinchón-Lorenzo S, Iniesta V, Parejo JC, Fernández-Cotrina J, Muñoz-Madrid R, Soto $\mathrm{M}$, et al. Detection of $<\mathrm{i}>$ Leishmania infantum $</ \mathrm{i}>$ kinetoplast minicircle DNA by Real Time PCR in hair of dogs with leishmaniosis. Veterinary parasitology. 2012.

[41] Oliveira LS, Rodrigues Fde M, Oliveira FS, Mesquita PR, Leal DC, Alcantara AC, et al. Headspace solid phase microextraction/gas chromatography-mass spectrometry combined to chemometric analysis for volatile organic compounds determination in canine hair: a new tool to detect dog contamination by visceral leishmaniasis. Journal of chromatography B, Analytical technologies in the biomedical and life sciences. 2008;875(2):392-8. Epub 2008/10/24.

[42] Magalhães-Junior JTM, P. R. R. ; Rodrigues, F. M. ; Oliveira, W. F. S. ; Franke, C.R.; Andrade, J.B.; Barrouin-Melo, S. M. Identification of biomarkers in the hair of dogs: new diagnostic possibilities in the study and control of visceral leishmaniasis. 2013.

[43] van der Greef J, Smilde AK. Symbiosis of chemometrics and metabolomics: past, present, and future. Journal of Chemometrics. 2005;19(5-7):376-86.

[44] Wilson IDN, J. K. Metabonomics and Global Systems Biology. In: Griffith WJ, editor. Metabolomics, metabonomics, and metabolite profiling: Royal Society of Chemistry; 2008. p. 295-314.

[45] Patti GJ, Yanes O, Siuzdak G. Innovation: Metabolomics: the apogee of the omics trilogy. Nature reviews Molecular cell biology. 2012;13(4):263-9.

[46] Fontana JM, Alexander E, Salvatore M. Translational research in infectious disease: current paradigms and challenges ahead. Translational Research. 2012;159(6):430-53.

[47] Smolinska A, Blanchet L, Buydens L, Wijmenga SS. NMR and pattern recognition methods in metabolomics: from data acquisition to biomarker discovery: a review. Analytica chimica acta. 2012;750:82-97.

[48] Issaq HJ, Van QN, Waybright TJ, Muschik GM, Veenstra TD. Analytical and statistical approaches to metabolomics research. Journal of separation science. 2009;32(13): 2183-99. 
[49] Ramautar R, Somsen GW, de Jong GJ. CE-MS for metabolomics: Developments and applications in the period 2010-2012. Electrophoresis. 2013;34(1):86-98.

[50] Lakshmanan V, Rhee KY, Daily JP. Metabolomics and malaria biology. Molecular and biochemical parasitology. 2011;175(2):104-11.

[51] Kell DB. Systems biology, metabolic modelling and metabolomics in drug discovery and development. Drug discovery today. 2006;11(23):1085-92.

[52] Henderson JP, Crowley JR, Pinkner JS, Walker JN, Tsukayama P, Stamm WE, et al. Quantitative metabolomics reveals an epigenetic blueprint for iron acquisition in uropathogenic Escherichia coli. PLoS pathogens. 2009;5(2):e1000305.

[53] Rodgers MA, Villareal VA, Schaefer EA, Peng LF, Corey KE, Chung RT, et al. Lipid metabolite profiling identifies desmosterol metabolism as a new antiviral target for hepatitis C virus. Journal of the American Chemical Society. 2012;134(16):6896-9.

[54] Willger SD, Grahl N, Cramer Jr RA. Aspergillus fumigatus metabolism: clues to mechanisms of in vivo fungal growth and virulence. Medical Mycology. 2009;47(S1):S72-S9.

[55] Olszewski KL, Morrisey JM, Wilinski D, Burns JM, Vaidya AB, Rabinowitz JD, et al. Host-Parasite Interactions Revealed by $<\mathrm{i}>$ Plasmodium falciparum $</ \mathrm{i}>$ Metabolomics. Cell host \& microbe. 2009;5(2):191-9.

[56] Arai M, Billker O, Morris HR, Panico M, Delcroix M, Dixon D, et al. Both mosquitoderived xanthurenic acid and a host blood-derived factor regulate gametogenesis of $<$ i $>$ Plasmodium $</ i>$ in the midgut of the mosquito. Molecular and biochemical parasitology. 2001;116(1):17-24.

[57] Saunders E, MacRae J, Naderer T, Ng M, McConville M, Likić V. LeishCyc: A Guide to Building a Metabolic Pathway Database and Visualization of Metabolomic Data. In: Navid A, editor. Microbial Systems Biology: Humana Press; 2012. p. 505-29.

[58] Silva AM, Cordeiro-da-Silva A, Coombs GH. Metabolic variation during development in culture of Leishmania donovani promastigotes. PLoS neglected tropical diseases. 2011;5(12):e1451.

[59] Berg M, Vanaerschot M, Jankevics A, Cuypers B, Maes I, Mukherjee S, et al. Metabolic adaptations of Leishmania donovani in relation to differentiation, drug resistance, and drug pressure. Molecular Microbiology. 2013:n/a-n/a.

[60] Phillips M, Cataneo RN, Condos R, Ring Erickson GA, Greenberg J, La Bombardi V, et al. Volatile biomarkers of pulmonary tuberculosis in the breath. Tuberculosis. 2007;87(1):44-52.

[61] Van Berkel J, Dallinga J, Möller G, Godschalk R, Moonen E, Wouters E, et al. A profile of volatile organic compounds in breath discriminates COPD patients from controls. Respiratory medicine. 2010;104(4):557-63. 
[62] Zhang A, Sun H, Xu H, Qiu S, Wang X. Cell Metabolomics. Omics: a journal of integrative biology. 2013.

[63] Dunn WB, Ellis DI. Metabolomics: current analytical platforms and methodologies. TrAC Trends in Analytical Chemistry. 2005;24(4):285-94.

[64] Zhang Z, Li G. A review of advances and new developments in the analysis of biological volatile organic compounds. Microchemical Journal. 2010;95(2):127-39.

[65] Kimbaris AC, Siatis NG, Daferera DJ, Tarantilis PA, Pappas CS, Polissiou MG. Comparison of distillation and ultrasound-assisted extraction methods for the isolation of sensitive aroma compounds from garlic ( $<\mathrm{i}>$ Allium sativum $</ \mathrm{i}>$ ). Ultrasonics sonochemistry. 2006;13(1):54-60.

[66] Chaintreau A. Simultaneous distillation-extraction: from birth to maturity-review. Flavour and fragrance journal. 2001;16(2):136-48.

[67] Pollien P, Chaintreau A. Simultaneous distillation-extraction: Theoretical model and development of a preparative unit. Analytical chemistry. 1997;69(16):3285-92.

[68] Hashemi P, Abolghasemi MM, Fakhari A, Ebrahimi SN, Ahmadi S. Hydrodistillation-solvent microextraction and GC-MS identification of volatile components of Artemisia aucheri. Chromatographia. 2007;66(3-4):283-6.

[69] Ferhat M, Tigrine-Kordjani N, Chemat S, Meklati B, Chemat F. Rapid extraction of volatile compounds using a new simultaneous microwave distillation: solvent extraction device. Chromatographia. 2007;65(3-4):217-22.

[70] Giannuzzo AN, Boggetti HJ, Nazareno MA, Mishima HT. Supercritical fluid extraction of naringin from the peel of Citrus paradisi. Phytochemical Analysis. 2003;14(4): 221-3.

[71] Stashenko EE, Jaramillo BE, Martínez JR. Analysis of volatile secondary metabolites from Colombian $<\mathrm{i}>$ Xylopia aromatica $</ \mathrm{i}>$ (Lamarck) by different extraction and headspace methods and gas chromatography. Journal of Chromatography A. 2004;1025(1):105-13.

[72] Stashenko EE, Puertas MA, Combariza MY. Volatile secondary metabolites from<i> Spilanthes americana $</ \mathrm{i}>$ obtained by simultaneous steam distillation-solvent extraction and supercritical fluid extraction. Journal of Chromatography A. 1996;752(1): 223-32.

[73] Crespo MP, Yusty ML. Comparison of supercritical fluid extraction and Soxhlet extraction for the determination of aliphatic hydrocarbons in seaweed samples. Ecotoxicology and Environmental Safety. 2006;64(3):400-5.

[74] Azmir J, Zaidul ISM, Rahman MM, Sharif KM, Mohamed A, Sahena F, et al. Techniques for extraction of bioactive compounds from plant materials: A review. Journal of Food Engineering. 2013;117(4):426-36. 
[75] MacLeod G, Ames JM. Comparative assessment of the artefact background on thermal desorption of Tenax GC and Tenax TA. Journal of Chromatography A. 1986;355:393-8.

[76] Dettmer K, Engewald W. Adsorbent materials commonly used in air analysis for adsorptive enrichment and thermal desorption of volatile organic compounds. Analytical and bioanalytical chemistry. 2002;373(6):490-500.

[77] Senf L, Frank H. Thermal-desorption of organic pollutants enriched on activated carbon.5. Desorption behavior and temperature profile. Journal of Chromatography. 1990;520:131-5.

[78] Leboda R, Łodyga A, Gierak A. Carbon adsorbents as materials for chromatography I. Gas chromatography. Materials Chemistry and Physics. 1997;51(3):216-32.

[79] Brown RH. What is the best sorbent for pumped sampling thermal desorption of volatile organic compounds? Experience with the EC sorbents project. Analyst. 1996;121(9):1171-5.

[80] Camel V, Caude M. Trace enrichment methods for the determination of organic pollutants in ambient air. Journal of Chromatography A. 1995;710(1):3-19.

[81] Dettmer K, Felix U, Engewald W, Mohnke M. Application of a unique selective PLOT capillary column for the analysis of oxygenated compounds in ambient air. Chromatographia. 2000;51:S221-S7.

[82] Sponring A, Filipiak W, Ager C, Schubert J, Miekisch W, Amann A, et al. Analysis of volatile organic compounds (VOCs) in the headspace of NCI-H1666 lung cancer cells. Cancer Biomarkers. 2010;7(3):153-61.

[83] Arthur CL, Pawliszyn J. Solid phase microextraction with thermal desorption using fused silica optical fibers. Analytical chemistry. 1990;62(19):2145-8.

[84] Penalver A, Pocurull E, Borrull F, Marcé R. Trends in solid-phase microextraction for determining organic pollutants in environmental samples. TrAC Trends in Analytical Chemistry. 1999;18(8):557-68.

[85] Ulrich S. Solid-phase microextraction in biomedical analysis. Journal of Chromatography A. 2000;902(1):167-94.

[86] Mills GA, Walker V. Headspace solid-phase microextraction procedures for gas chromatographic analysis of biological fluids and materials. Journal of Chromatography A. 2000;902(1):267-87.

[87] Augusto F, Leite e Lopes A, Zini CA. Sampling and sample preparation for analysis of aromas and fragrances. TrAC Trends in Analytical Chemistry. 2003;22(3):160-9.

[88] Grote C, Pawliszyn J. Solid-phase microextraction for the analysis of human breath. Analytical chemistry. 1997;69(4):587-96. 
[89] Hyšpler Rr, Crhová Š, Gasparič J, Zadák Z, Čižková M, Balasová V. Determination of isoprene in human expired breath using solid-phase microextraction and gas chromatography-mass spectrometry. Journal of Chromatography B: Biomedical Sciences and Applications. 2000;739(1):183-90.

[90] Wu D, Wang Z, Wang H, Zhang L, Wang X. Analysis of odors in human palm by GC/MS with headspace solid phase microextraction. Modern Scientific Instruments. 2003;4:52-4.

[91] Wang Y, Zhao M. Analysis of volatile constituents of Thymus Amurensis Klokov by gas chromatography-mass spectrometry with solid-phase microextraction. Chinese Journal of Analytical Chemistry. 2004;32(2):272-.

[92] Jirovetz L, Buchbauer G, Ngassoum MB, Geissler M. Aroma compound analysis of< i $>$ Piper nigrum $</ i>$ and $<\mathrm{i}>$ Piper guineense $</ \mathrm{i}>$ essential oils from Cameroon using solid-phase microextraction-gas chromatography, solid-phase microextraction-gas chromatography-mass spectrometry and olfactometry. Journal of Chromatography A. 2002;976(1):265-75.

[93] Sánchez-Palomo E, Diaz-Maroto MC, Pérez-Coello MS. Rapid determination of volatile compounds in grapes by HS-SPME coupled with GC-MS. Talanta. 2005;66(5): 1152-7.

[94] Augusto F, Valente ALP, dos Santos Tada E, Rivellino SR. Screening of Brazilian fruit aromas using solid-phase microextraction-gas chromatography-mass spectrometry. Journal of Chromatography A. 2000;873(1):117-27.

[95] Crespo R, Pedrini N, Juárez M, Dal Bello G. Volatile organic compounds released by the entomopathogenic fungus $<\mathrm{i}>$ Beauveria bassiana $</ \mathrm{i}>$. Microbiological research. 2008;163(2):148-51.

[96] Hachem C, Fazio P, Rao J, Bartlett K, Chaubey YP. Identification and transport investigation of microbial volatile organic compounds in full-scale stud cavities. Building and Environment. 2009;44(8):1691-8.

[97] Souza Silva EA, Risticevic S, Pawliszyn J. Recent trends in SPME concerning sorbent materials, configurations and $<\mathrm{i}>$ in vivo $</ \mathrm{i}>$ applications. TrAC Trends in Analytical Chemistry. 2012.

[98] Ouyang G, Vuckovic D, Pawliszyn J. Nondestructive sampling of living systems using in vivo solid-phase microextraction. Chemical Reviews. 2011;111(4):2784-814.

[99] Bai Z, Pilote A, Sarker PK, Vandenberg G, Pawliszyn J. In Vivo Solid-Phase Microextraction with in Vitro Calibration: Determination of Off-Flavor Components in Live Fish. Analytical chemistry. 2013;85(4):2328-32.

[100] Etiévant PX, Callement G, Langlois D, Issanchou S, Coquibus N. Odor intensity evaluation in gas chromatography-olfactometry by finger span method. Journal of agricultural and food chemistry. 1999;47(4):1673-80. 
[101] Sanchez JM, Sacks RD. GC analysis of human breath with a series-coupled column ensemble and a multibed sorption trap. Analytical chemistry. 2003;75(10):2231-6.

[102] Bean HD, Dimandja J-MD, Hill JE. Bacterial volatile discovery using solid phase microextraction and comprehensive two-dimensional gas chromatography-time-offlight mass spectrometry. Journal of Chromatography B. 2012;901:41-6.

[103] Stadler S, Stefanuto P-H, Brokl M, Forbes SL, Focant J-Fo. Characterization of Volatile Organic Compounds from Human Analogue Decomposition Using Thermal Desorption Coupled to Comprehensive Two-Dimensional Gas Chromatography-Time-ofFlight Mass Spectrometry. Analytical chemistry. 2012;85(2):998-1005.

[104] Dieterle F, Marrer E. New technologies around biomarkers and their interplay with drug development. Analytical and bioanalytical chemistry. 2008;390(1):141-54.

[105] Denoroy L, Zimmer L, Renaud B, Parrot S. Ultra high performance liquid chromatography as a tool for the discovery and the analysis of biomarkers of diseases: A review. Journal of Chromatography B. 2013;927(0):37-53.

[106] Koulman A, Lane GA, Harrison SJ, Volmer DA. From differentiating metabolites to biomarkers. Analytical and bioanalytical chemistry. 2009;394(3):663-70.

[107] Katajamaa M, Orešič M. Data processing for mass spectrometry-based metabolomics. Journal of Chromatography A. 2007;1158(1-2):318-28.

[108] Trygg J, Holmes E, Lundstedt T. Chemometrics in metabonomics. Journal of proteome research. 2007;6(2):469-79.

[109] LU G, WANG J, ZHAO X, KONG H, XU G. Study on gender difference based on metabolites in urine by ultra high performance liquid chromatography/time of flight mass spectrometry. Chinese Journal of Chromatography. 2006;24(2):109-13.

[110] Stella C, Beckwith-Hall B, Cloarec O, Holmes E, Lindon JC, Powell J, et al. Susceptibility of human metabolic phenotypes to dietary modulation. Journal of proteome research. 2006;5(10):2780-8.

[111] Wang W, Feng B, Li X, Yin P, Gao P, Zhao X, et al. Urinary metabolic profiling of colorectal carcinoma based on online affinity solid phase extraction-high performance liquid chromatography and ultra performance liquid chromatography-mass spectrometry. Molecular BioSystems. 2010;6(10):1947-55.

[112] Wang TJ, Larson MG, Vasan RS, Cheng S, Rhee EP, McCabe E, et al. Metabolite profiles and the risk of developing diabetes. Nature medicine. 2011;17(4):448-53.

[113] Langenberg C, Savage DB. An amino acid profile to predict diabetes? Nature medicine. 2011;17(4):418.

[114] Orešič M, Simell S, Sysi-Aho M, Näntö-Salonen K, Seppänen-Laakso T, Parikka V, et al. Dysregulation of lipid and amino acid metabolism precedes islet autoimmunity in 
children who later progress to type 1 diabetes. The Journal of experimental medicine. 2008;205(13):2975-84.

[115] Woo HM, Kim KM, Choi MH, Jung BH, Lee J, Kong G, et al. Mass spectrometry based metabolomic approaches in urinary biomarker study of women's cancers. Clinica Chimica Acta. 2009;400(1):63-9.

[116] Sabatine MS, Liu E, Morrow DA, Heller E, McCarroll R, Wiegand R, et al. Metabolomic identification of novel biomarkers of myocardial ischemia. Circulation. 2005;112(25):3868-75.

[117] Jensen UG, Brandt NJ, Christensen E, Skovby F, Nørgaard-Pedersen B, Simonsen H. Neonatal screening for galactosemia by quantitative analysis of hexose monophosphates using tandem mass spectrometry: a retrospective study. Clinical chemistry. 2001;47(8):1364-72.

[118] Liu G, Snapp HM, Ji QC, Arnold ME. Strategy of accelerated method development for high-throughput bioanalytical assays using ultra high-performance liquid chromatography coupled with mass spectrometry. Analytical chemistry. 2009;81(22): 9225-32.

[119] Denery JR, Nunes AA, Hixon MS, Dickerson TJ, Janda KD. Metabolomics-based discovery of diagnostic biomarkers for onchocerciasis. PLoS neglected tropical diseases. 2010;4(10):e834.

[120] Rudnicka J, Kowalkowski T, Ligor T, Buszewski B. Determination of volatile organic compounds as biomarkers of lung cancer by SPME-GC-TOF/MS and chemometrics. Journal of Chromatography B. 2011;879(30):3360-6.

[121] Phillips M, Boehmer JP, Cataneo RN, Cheema T, Eisen HJ, Fallon JT, et al. Prediction of heart transplant rejection with a breath test for markers of oxidative stress. The American journal of cardiology. 2004;94(12):1593-4.

[122] Matsumura K, Opiekun M, Oka H, Vachani A, Albelda SM, Yamazaki K, et al. Urinary volatile compounds as biomarkers for lung cancer: a proof of principle study using odor signatures in mouse models of lung cancer. PloS one. 2010;5(1):e8819.

[123] Logan JG, Birkett MA. Semiochemicals for biting fly control: their identification and exploitation. Pest Management Science. 2007;63(7):647-57.

[124] Andrade AJ, Andrade MR, Dias ES, Pinto MC, Eiras AE. Are light traps baited with kairomones effective in the capture of Lutzomyia longipalpis and Lutzomyia intermedia? An evaluation of synthetic human odor as an attractant for phlebotomine sand flies (Diptera: Psychodidae: Phlebotominae). Memorias do Instituto Oswaldo Cruz. 2008;103(4):337-43. Epub 2008/07/29.

[125] Dicke M, Sabelis MW. Infochemical terminology: based on cost-benefit analysis rather than origin of compounds? Functional Ecology. 1988:131-9. 
[126] Kelly DW, Mustafa Z, Dye C. Differential application of lambda-cyhalothrin to control the sandfly Lutzomyia longipalpis. Medical and veterinary entomology. 1997;11(1):13-24. Epub 1997/01/01.

[127] Corrêa A, Sant'Ana J. Ecologia química de insetos. Produtos naturais no controle de insetos São Carlos: Editora UFSCar. 2007:150.

[128] Knols BGJ, Meijerink J. Odors influence mosquito behavior. Science and Medicine. 1997;4:56-63.

[129] Eiras AE, Jepson PC. Host location by Aedes aegypti (Diptera: Culicidae): a wind tunnel study of chemical cues. Bulletin of entomological research. 1991;81(02):151-60.

[130] Mboera L, Takken W, Sambu E. The response of Culex quinquefasciatus (Diptera: Culicidae) to traps baited with carbon dioxide, 1-octen-3-ol, acetone, butyric acid and human foot odour in Tanzania. Bulletin of entomological research. 2000;90(02):155-9.

[131] Pinto MC, Campbell-Lendrum DH, Lozovei AL, Teodoro U, Davies CR. Phlebotomine sandfly responses to carbon dioxide and human odour in the field. Medical and veterinary entomology. 2001;15(2):132-9. Epub 2001/07/04.

[132] Torr S. Dose responses of tsetse flies (Glossina) to carbon dioxide, acetone and octenol in the field. Physiological Entomology. 1990;15(1):93-103.

[133] Kline D, Takken W, Wood J, Carlson D. Field studies on the potential of butanone, carbon dioxide, honey extract, 1-octen-3-ol, L-lactic acid and phenols as attractants for mosquitoes*. Medical and veterinary entomology. 1990;4(4):383-91.

[134] Bray DP, Ward RD, Hamilton JG. 9. The chemical ecology of sandflies. Olfaction in vector-host interactions. The Netherlands: Wageningen Academic Publishers; 2010. p. 203.

[135] Grant AJ, O'Connell R. The detection of carbon dioxide and its role in the orientation to hosts by haematophagous insects. Olfaction in vector-host interactions. The Netherlands: Wageningen Academic Publishers; 2010. p. 91-113.

[136] Morton IE, Ward RD. Laboratory response of female Lutzomyia longipalpis sandflies to a host and male pheromone source over distance. Medical and veterinary entomology. 1989;3(3):219-23. Epub 1989/07/01.

[137] Hamilton JGC, Hooper AM, Ibbotson HC, Kurosawa S, Mori K, Muto S-E, et al. 9methylgermacrene- $\mathrm{B}$ is confirmed as the sex pheromone of the sandfly Lutzomyia longipalpis from lapinha, Brazil, and the absolute stereochemistry defined as S. Chemical communications. 1999(23):2335-6.

[138] Hamilton J, Maingon R, Alexander B, Ward R, Brazil R. Analysis of the sex pheromone extract of individual male Lutzomyia longipalpis sandflies from six regions in Brazil. Medical and veterinary entomology. 2005;19(4):480-8. 
[139] Rebollar-Tellez E, Hamilton J, Ward R. Biting site selection on a human volunteer by members of the Lutzomyia longipalpis complex. Southwestern Entomologist. 2002;27(1):97-104.

[140] Uribe S. The status of the Lutzomyia longipalpis species complex and possible implications for Leishmania transmission. Memorias do Instituto Oswaldo Cruz. 1999;94(6):729-34.

[141] Jones TM, Hamilton JGC. A role for pheromones in mate choice in a lekking sandfly. Animal behaviour. 1998;56(4):891-8. Epub 1998/12/16.

[142] Bray DP, Alves GB, Dorval ME, Brazil RP, Hamilton JG. Synthetic sex pheromone attracts the leishmaniasis vector Lutzomyia longipalpis to experimental chicken sheds treated with insecticide. Parasites \& vectors. 2010;3:16. Epub 2010/03/13.

[143] Bray D, Hamilton JGC. Host odor synergizes attraction of virgin female Lutzomyia longipalpis (Diptera: Psychodidae). Journal of medical entomology. 2007;44(5): 779-87.

[144] Hamilton J, Ramsoondar T. Attraction of Lutzomyia longipalpis to human skin odours. Medical and veterinary entomology. 1994;8(4):375-80.

[145] Rebollar-Tellez E, Hamilton J, Ward R. Response of female Lutzomyia longipalpis to host odour kairomones from human skin. Physiological Entomology. 1999;24(3): 220-6.

[146] Rebollar-Téllez E, Hamilton J, Ward R. Genetic inherence of the response to human kairomones by two allopatric members of the Lutzomyia longipalpis complex. Physiological Entomology. 2006;31(1):94-7.

[147] Dougherty MJ, Guerin PM, Ward RD, Hamilton JGC. Behavioural and electrophysiological responses of the phlebotomine sandfly Lutzomyia longipalpis (Diptera: Psychodidae) when exposed to canid host odour kairomones. Physiological Entomology. 1999;24(3):251-62.

[148] O'Shea B, Rebollar-Tellez E, Ward RD, Hamilton JG, el Naiem D, Polwart A. Enhanced sandfly attraction to Leishmania-infected hosts. Transactions of the Royal Society of Tropical Medicine and Hygiene. 2002;96(2):117-8. Epub 2002/06/12.

[149] Keil TA. Morphology and development of the peripheral olfactory organs. In: Hansson BS, editor. Insect olfaction. Germany, Berlin: Springer; 1999.

[150] Bradbury JW, Vehrencamp SL. Principles of animal communication 2011.

[151] Park KC, Ochieng SA, Zhu J, Baker TC. Odor Discrimination using Insect Electroantennogram Responses from an Insect Antennal Array. Chemical Senses. 2002;27(4): 343-52.

[152] Witzgall P, Kirsch P, Cork A. Sex pheromones and their impact on pest management. Journal of chemical ecology. 2010;36(1):80-100. 
[153] Spiegel CN, Jeanbourquin P, Guerin PM, Hooper AM, Claude S, Tabacchi R, et al. (1S,3S,7R)-3-methyl-alpha-himachalene from the male sandfly Lutzomyia longipalpis (Diptera: Psychodidae) induces neurophysiological responses and attracts both males and females. Journal of insect physiology. 2005;51(12):1366-75. Epub 2005/10/18.

[154] Sant'ana AL, Eiras AE, Cavalcante RR. Electroantennographic responses of the Lutzomyia (Lutzomyia) longipalpis (Lutz \& Neiva) (Diptera: Psychodidae) to 1-octen-3ol. Neotropical entomology. 2002;31:13-7.

[155] Trimble R, Marshall D. Quantitative method for pheromone delivery in studies of sensory adaptation of moth antennae. Physiological Entomology. 2007;32(4):388-93.

[156] Pinto MC, Bray DP, Eiras AE, Carvalheira HP, Puertas CP. Attraction of the cutaneous leishmaniasis vector Nyssomyia neivai (Diptera: Psychodidae) to host odour components in a wind tunnel. Parasites \& vectors. 2012;5(1):210.

[157] Dias-Lima AG, Guedes ML, Sherlock IA. Horizontal stratification of the sand fly fauna (Diptera: Psychodidae) in a transitional vegetation between caatinga and tropical rain forest, state of Bahia, Brazil. Memorias do Instituto Oswaldo Cruz. 2003;98(6): 733-7. Epub 2003/11/05.

[158] Werneck GL. Forum: geographic spread and urbanization of visceral leishmaniasis in Brazil. Introduction. Cadernos de saude publica / Ministerio da Saude, Fundacao Oswaldo Cruz, Escola Nacional de Saude Publica. 2008;24(12):2937-40. Epub 2008/12/17.

[159] Alexander B, Maroli M. Control of phlebotomine sandflies. Medical and veterinary entomology. 2003;17(1):1-18.

[160] Amóra SS, Bevilaqua CM, Feijó F, Alves ND, Maciel MdV. Control of phlebotomine (Diptera: Psychodidae) leishmaniasis vectors. Neotropical entomology. 2009;38(3): 303-10.

[161] Andrade AJd. Ecologia química de flebotomíneos (Diptera : Psychodidae: Phlebotominae): desenvlvimento de uma armadilha e análise dos hidrocarbonetos cuticulares das espécies. Belo Horizonte, Minas Gerais: Universidade Federal de Minas Gerais; 2010.

[162] Kasili S, Kutima H, Mwandawiro C, Ngumbi PM, Anjili CO. Comparative attractiveness of $\mathrm{CO}(2)$-baited $\mathrm{CDC}$ light traps and animal baits to Phlebotomus duboscqi sandflies. Journal of vector borne diseases. 2009;46(3):191-6. Epub 2009/09/03.

[163] Morton IE, Ward RD. Response of female sandflies (Lutzomyia longipalpis) to pheromone-baited sticky traps in the laboratory. Annals of tropical medicine and parasitology. 1990;84(1):49-51. Epub 1990/02/01.

[164] Tchouassi DP, Sang R, Sole CL, Bastos AD, Mithoefer K, Torto B. Sheep skin odor improves trap captures of mosquito vectors of Rift Valley fever. PLoS neglected tropical diseases. 2012;6(11):e1879. 
[165] Verhulst NO, Mukabana WR, Takken W, Smallegange RC. Human skin microbiota and their volatiles as odour baits for the malaria mosquito Anopheles gambiae ss. Entomologia Experimentalis et Applicata. 2011;139(2):170-9.

[166] Shani A. Chemical communication agents (pheromones) in integrated pest management. Drug development research. 2000;50(3-4):400-5.

[167] Bray DP, Alves GB, Dorval ME, Brazil RP, Hamilton J. Research Synthetic sex pheromone attracts the leishmaniasis vector Lutzomyia longipalpis to experimental chicken sheds treated with insecticide. 2010. 